\title{
Myocardial contractile response to dobutamine in hypoplastic left heart syndrome post-Fontan
}

\author{
James Wong ${ }^{1,2^{*}}$, Kuberan Pushparajah ${ }^{1,2}$, Adelaide De Vecchi ${ }^{1}$, Gerald F Greil ${ }^{1,2}$, Tarique Hussain ${ }^{1,2}$, Reza Razavi ${ }^{1,2}$ \\ From 17th Annual SCMR Scientific Sessions \\ New Orleans, LA, USA. 16-19 January 2014
}

\section{Background}

The systemic right ventricle (RV) is at increased risk of developing heart failure. Combined MRI-catheterization (XMR) techniques offer a unique opportunity to study this condition. We assess pressure-volume relations in children with hypoplastic left heart syndrome (HLHS) post Fontan with stepwise increments of dobutamine stress.

\section{Methods}

Prospective data from anesthetized patients with HLHS undergoing clinical XMR were analyzed. A fluid filled MR compatible catheter placed in the systemic RV recorded pressures at rest, with dobutamine infusion at $10 \mathrm{mcg} / \mathrm{kg} /$ min and at $20 \mathrm{mcg} / \mathrm{kg} / \mathrm{min}$. Simultaneous cine short axis stacks of the ventricle were performed. Pressure-volume loops were constructed. End-systolic pressure-volume relationship was derived at each state from a validated maximal pressure (Pmax) estimation method. Ventriculoarterial coupling (Ees:Ea) was compared to myocardial power and overall global function.

\section{Results}

Five patients with HLHS and exercise intolerance, mean age 7.8 years (range $3.5-11.6$ yrs), weight $26 \mathrm{Kg}$ (range 16$46 \mathrm{Kg}$ ), time since Fontan completion (mean 3.2 years). No significant tricuspid regurgitation in any patient. Statistical analysis was performed using one-way ANOVA with post-hoc comparisons to assess subgroup variation where $\mathrm{p}<0.05$. There were significant increases in EF, indexed cardiac output, power and ventricular contractility (Ees) with increases limited to between rest and dobutamine $10(\mathrm{p}<0.01)$ with no further significant increase at 20. iEDV fell significantly between rest and dobutamine 20 ( $\mathrm{p}<0.01)$. EDP and arterial elastance (Ea) did not change throughout. Ees:Ea increased between rest and

${ }^{1}$ Imaging Sciences, Kings College London, London, UK

Full list of author information is available at the end of the article dobutamine 10 only. $\mathrm{dP} / \mathrm{dtmin}$ a measure of rate of relaxation fell with dobutamine 10 only.

\section{Conclusions}

In the systemic RV, load independent indices of contraction in response to dobutamine are similar to those recorded in the healthy left ventricle (LV). The systemic $\mathrm{RV}$ at rest works neither at maximal mechanical efficiency $($ Ees:Ea $=2)$ nor maximal stroke work efficiency at a given EDV (Ees:Ea = 1). Increased coupling with dobutamine, mediated through increased myocardial contractility, indicates at higher heart rates the RV moves towards improved mechanical efficiency though at higher levels of overall energy expenditure. The relative increase in stroke work (37\%) is comparable to data published on the healthy LV. The systemic RV has a limited cardiac reserve. Despite appropriate responses in contractility to low dose dobutamine, the heart is unable to further augment power and cardiac output with administration of dobutamine 20 . Indeed, the plateauing of $\mathrm{dP} / \mathrm{dtmin}$ - a measure of relaxation - indicates that in the presence of tachycardia there is failure to adequately fill the heart. Hence cardiac output and contractility may be limited by a ceiling of maximal flow through the Fontan circuit. This gives us valuable insights into the physiology of children with HLHS postFontan.

\section{Funding}

The Division of Imaging Sciences receives support as the Centre of Excellence in Medical Engineering (funded by the Wellcome Trust and EPSRC; grant number WT 088641/Z/09/Z) as well as the BHF Centre of Excellence (British Heart Foundation award RE/08/03). This work was also supported by the European Commission (FP7ICT-224485:euHeart). The authors acknowledge financial support from the Department of Health via the National Institute for Health Research (NIHR) comprehensive 
Table 1 Mean changes in parameters

\begin{tabular}{|c|c|c|c|c|c|}
\hline & & Rest & Dobutamine $10 \mathrm{mcg} / \mathrm{kg} / \mathrm{min}$ & Dobutamine $20 \mathrm{mcg} / \mathrm{kg} / \mathrm{min}$ & $P$ values \\
\hline Heart rate & bpm & 63 & 111 & 137 & \\
\hline Ejection fraction & $\%$ & 51.4 & 65.4 & 65.8 & 0.01 \\
\hline Power & Watts & 14.99 & 35.41 & 30.07 & 0.00007 \\
\hline Indexed Cardiac output & $1 / \min$ & 2.3 & 4.3 & 4.5 & 0.00002 \\
\hline End Diastolic Pressure & $\mathrm{mmHg}$ & 8.2 & 6.6 & 6.2 & 0.4 \\
\hline $\mathrm{dP} / \mathrm{dt} \max$ & $\mathrm{mmHg} / \mathrm{ms}$ & 0.79 & 2.53 & 2.35 & 0.004 \\
\hline $\mathrm{dP} / \mathrm{dt} \min$ & $\mathrm{mmHg} / \mathrm{ms}$ & -0.92 & -1.81 & -1.80 & 0.002 \\
\hline Ees & $\mathrm{mmHg} / \mathrm{ml}$ & 3.25 & 5.86 & 5.45 & 0.007 \\
\hline $\mathrm{Ea}$ & $\mathrm{mmHg} / \mathrm{ml}$ & 2.2 & 2.7 & 3.2 & 0.2 \\
\hline Ees:Ea & & 1.5 & 2.2 & 1.8 & 0.004 \\
\hline Indexed End diastolic volume & $\mathrm{ml} / \mathrm{m} 2$ & 71 & 59 & 49 & 0.001 \\
\hline
\end{tabular}

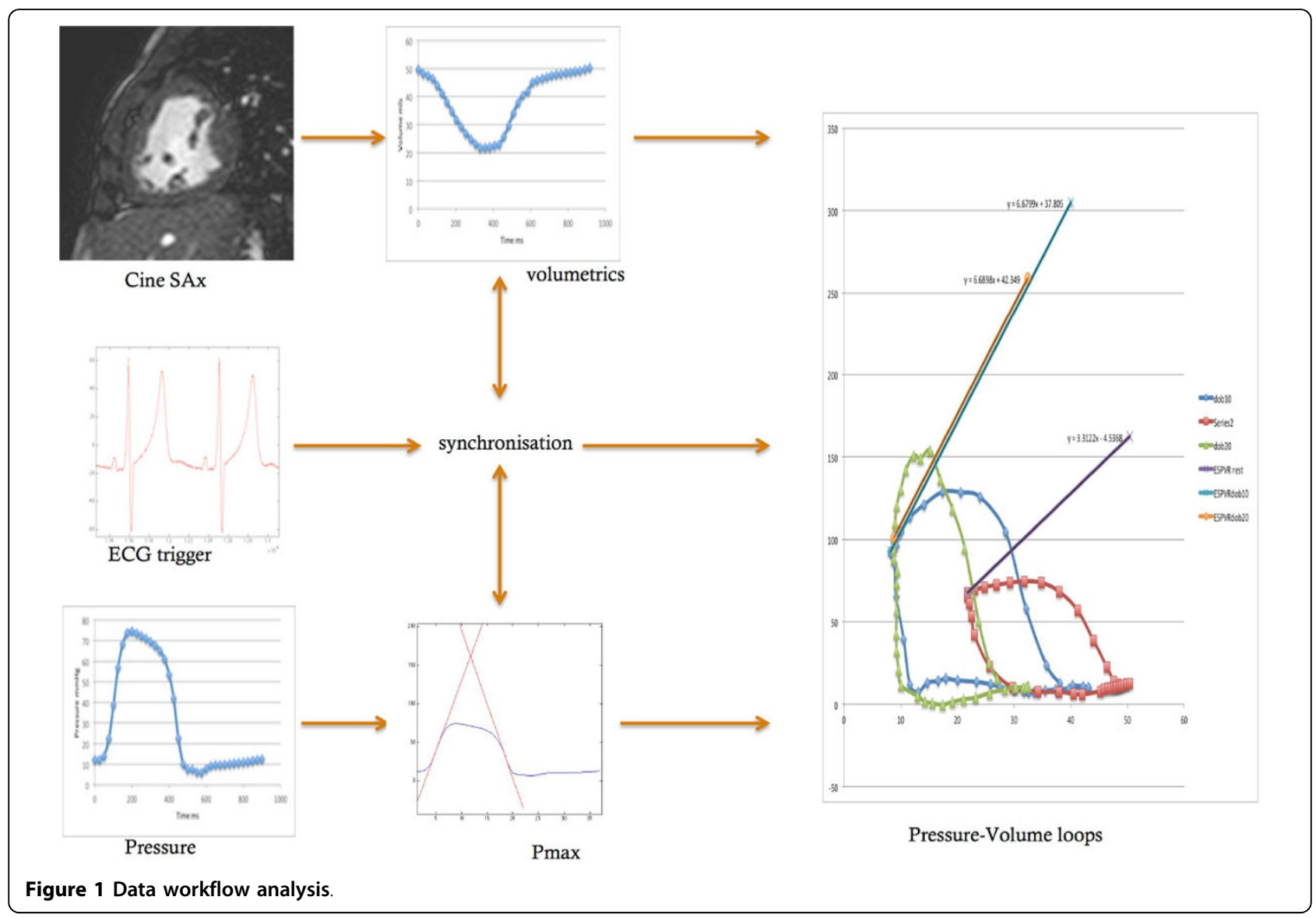

Biomedical Research Centre award to Guy's \& St Thomas' NHS Foundation Trust in partnership with King's College London and King's College Hospital NHS Foundation Trust.

\section{Authors' details}

${ }^{1}$ Imaging Sciences, Kings College London, London, UK. ${ }^{2}$ Paediatric Cardiology, St Thomas' Hospital, London, UK.
Published: 16 January 2014

doi:10.1186/1532-429X-16-S1-0104

Cite this article as: Wong et al:: Myocardial contractile response to dobutamine in hypoplastic left heart syndrome post-Fontan. Journal of

Cardiovascular Magnetic Resonance 2014 16(Suppl 1):0104. 